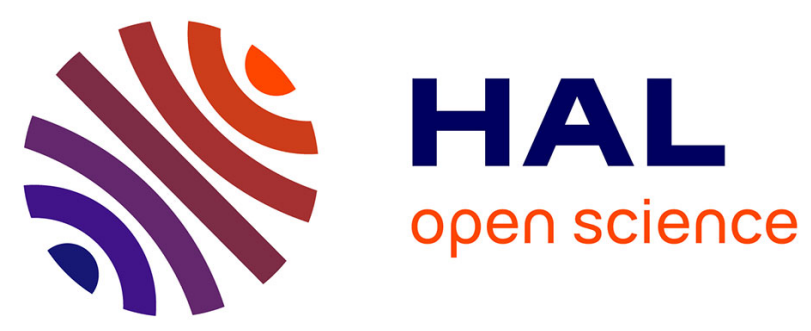

\title{
High performance finned-tube heat exchangers based on filled polymer
}

\author{
Joseph Jabbour, Serge Russeil, Mohammed Mobtil, Daniel Bougeard, \\ Marie-France Lacrampe, Patricia Krawczak
}

\section{- To cite this version:}

Joseph Jabbour, Serge Russeil, Mohammed Mobtil, Daniel Bougeard, Marie-France Lacrampe, et al.. High performance finned-tube heat exchangers based on filled polymer. Applied Thermal Engineering, 2019, 155, pp.620-630. 10.1016/j.applthermaleng.2019.04.036 . hal-02100866

\section{HAL Id: hal-02100866 https://hal.science/hal-02100866}

Submitted on 22 Oct 2021

HAL is a multi-disciplinary open access archive for the deposit and dissemination of scientific research documents, whether they are published or not. The documents may come from teaching and research institutions in France or abroad, or from public or private research centers.
L'archive ouverte pluridisciplinaire HAL, est destinée au dépôt et à la diffusion de documents scientifiques de niveau recherche, publiés ou non, émanant des établissements d'enseignement et de recherche français ou étrangers, des laboratoires publics ou privés.

\section{다)(1) $(5$}

Distributed under a Creative Commons Attribution - NonCommercial| 4.0 International 


\title{
High performance finned-tube heat Exchangers based on filled polymer
}

\author{
Joseph Jabbour $^{\text {a,b,c }}$, Serge Russeil ${ }^{\text {a,c* }}$, Mohammed Mobtil ${ }^{\mathrm{a}, \mathrm{c}}$, Daniel Bougeard ${ }^{\mathrm{a}, \mathrm{c}}$ \\ Marie-France Lacrampe ${ }^{\text {b,c }}$, Patricia Krawczak ${ }^{\text {b,c }}$ \\ ${ }^{a}$ IMT Lille Douai, Energy Engineering Department, F-59508, Douai, France \\ ${ }^{b}$ IMT Lille Douai, Polymer and Composites Technology \& Mechanical Engineering Department, F-59508, Douai, France \\ ${ }^{c}$ University of Lille, F-59000 Lille, France
}

\begin{abstract}
This paper aims to check the possibility of substitute metal by filled thermoplastic materials for making finnedtube Heat Exchangers (for HVAC applications, heat recovery ...). The influence of low thermal conductivity of a filled polymer on the overall thermal performance of a compact finned-tube Heat Exchanger was numerically analyzed, via Computational fluid dynamics (CFD) simulations. The effect of geometrical parameters such as the tube diameter, tube pitch, fin pitch and fin thickness on the compactness, mass, heat exchange duty, and pressure drop of the heat exchanger (of fixed initial dimensions) was highlighted. Finally, the numerical results showed that the low conductivity of such polymeric materials could be compensated by the optimization of geometric parameters to reach performances similar to those of a metallic compact HX.
\end{abstract}

Keywords: finned-tube heat exchanger, thermoplastics, polymer, thermal conductivity, Computational fluid dynamics.
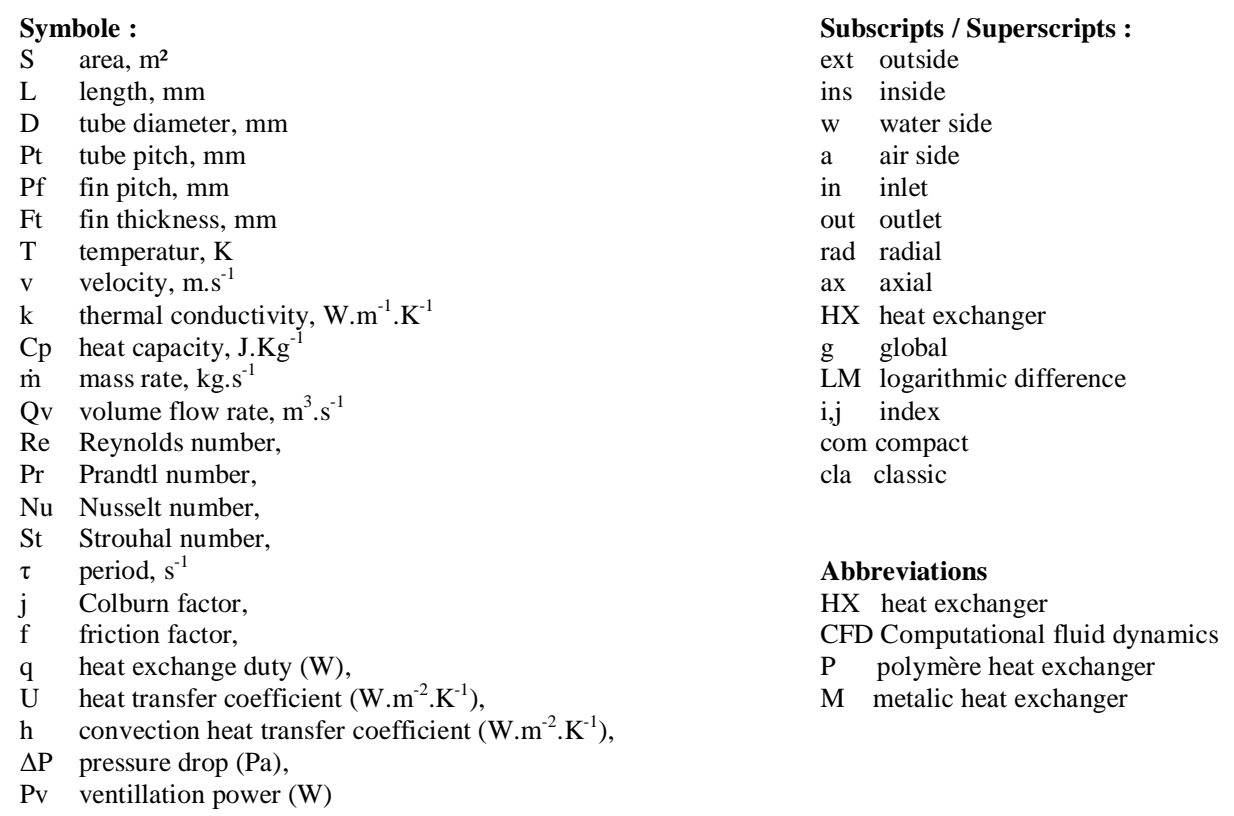

\section{Introduction}

Heat Exchangers (HXs) are vital components for many industrial processes. Their overall thermal performance and dimensions have a direct impact on process efficiency and their cost. In this context, many studies in the literature tried to increase the overall performance of HXs, extend their life time and reduce their size and thus their cost. Finned-tube heat exchanger is a well-known HX type used as aero-refrigerant in many industrial applications such as waste heat recovery, heating/cooling of buildings and vehicles. This type of HX contains thin plates (fin) as an extension area on gas side in order to improve the exchange area. These fins are normally made from thermal conductor materials (as aluminum) in order to insure a high fin efficiency and in consequence an important enhancement of the global heat performance. However, metallic HXs have many drawbacks regarding weight and cost. Thus, the substitution of metals by polymeric materials could be of major interest due to their lightness and cheapness, their high processability, recyclability and chemical and corrosion resistance. In addition this substitution could be directly related to sustainable development by saving raw materials. But, 
polymers are thermal insulants and their thermal conductivity is 100 to 1000 times lower than that of metallic materials. Thus, their use to make HX requires to find solutions of at least two major issues: (i) increasing their thermal conductivity and/or (ii) enhancing the HX efficiency by a more compact geometrical design.

The increase of the polymer overall effective thermal conductivity can be achieved by filling the polymer matrix with conductive charges or by controlling its crystallinity [1]. Thus, Cvallos et al. [2] proved experimentally that the specific volume- heat transfer coefficient $\left(\mathrm{kW} \cdot \mathrm{m}^{-3} \cdot \mathrm{K}^{-1}\right)$ of a "webbed-tube" made of polyamide 12 filled with carbon fibers is 1.65 times higher than that produced with a neat polyamide 12. Moreover, Felber and Nellis [12] showed analytically and experimentally for a plat and fin HX that it is not necessary to achieve the thermal conductivity of metallic material to obtained sufficient heat exchanger efficiency. They demonstrated that the thermal performance increased logarithmically with the material conductivity so that it is possible to reach about $80 \%$ of the thermal performance of a metallic exchanger with a material with moderated thermal conductivity (about $20 \mathrm{~W} \cdot \mathrm{m}^{-1} \cdot \mathrm{K}^{-1}$ ). Mamunya and al [3] demonstrated that the effective thermal conductivity of so filled materials mainly depends more on the filler geometry and content than on the thermal properties of their constituents. Adding 1D fillers in a polymeric matrix leads to the formation of an anisotropic composite whose radial $\left(\mathrm{k}_{\mathrm{rad}}\right)$ and axial thermal conductivities range from 15 and $20 \mathrm{~W} \mathrm{~m} \cdot \mathrm{K}^{-1}$ and 2.5 and $3.5 \mathrm{~W} \mathrm{~m}^{-1} \cdot \mathrm{K}^{-1}$ respectively. A polymer filled with 2D particles (carbon or metallic platelets) is also anisotropic and its radial and axial conductivities vary from 8 to $12 \mathrm{~W} \cdot \mathrm{m}^{-1} \cdot \mathrm{K}^{-1}$ and from 1.5 to $2 \mathrm{~W} \mathrm{~m}^{-1} \cdot \mathrm{K}^{-1}$ respectively. Finally, a polymeric composite containing 3D fillers (metallic spheres for example) is mainly isotropic and its thermal conductivity cannot reach higher values than $4.5 \mathrm{~W} \cdot \mathrm{m}^{-1} \cdot \mathrm{K}[4][5][6]$. Thus the gap between filled polymer (1-D fillers) and metallic materials is reduced to a factor of 20 (instead of 1000).

Former studies [7], [8] showed that heat exchangers made of polymers with low thermal conductivity $(<1 \mathrm{~W} \mathrm{~m}$ ${ }^{1} \cdot \mathrm{K}^{-1}$ ) can meet interesting overall thermal performances by means of an enhancement of their compactness. For liquid-liquid HX, Scheffler et al. [9] showed that the substitution of metal by filled polymer without losing the thermal exchange efficiency requires significant reduction of the tube thickness. Zaekadas and Sirka [10] obtained the same result by an increase in surface exchange (simultaneous reduction in tube diameter and thickness). The case of the liquid-gas HX is more complicated. In this case, the thermal resistance of air (gas) is so high that the exchange surface on the gas side must be significantly larger. For that purpose, one can use surface extensions (fins) or specific plate geometry designs. Haris et al. [11] for example, made a cross flow micro HX made of PMMA having a higher heat exchange per unit volume and per unit mass than those of a metallic one (made of aluminum or titanium), by reducing the channels size. More sophisticated designs can also be used to achieve the same result. For example, Haertel and Nellis [12] combined the design flexibility of 3D printing with the topological approach to manufacture a new architecture of plate fin HX and compensate the low conductivity of the overall charged polymer. Nevertheless, in these cases, the gas-side pressure drop is important bringing limitation to certain applications (such as heating and air conditioning). Indeed this pressure drop is directly related to the ventilation power which is proportional to the volume flow rate of the gas. This volume flow rate of gas being by far the largest flow rate in a liquid gas exchanger, this pressure drop is the main component of the operating cost of the exchanger. In the case of gas-liquid, it is crucial to keep air pressure drop values as low as possible. For this reason, fin-tube HX presents the best compromise between thermal performance and pressure loss by using a surface extension air-side (dominant thermal resistance side), and consequently, ensuring a sufficient passage section of the air. In this context, Chen and $\mathrm{Li}$ [13], while using filled polymer with thermal conductivity between 15 and 25 for this type of HX, showed that for a classic geometry with normal geometric parameters the global thermal coefficient is $70 \%$ of that of aluminum HX.

On this basis, the present paper aims to compensate the gap between polymer and metallic heat exchanger by combined filled polymer (1-D filler) of thermal conductivity between 15 and $20 \mathrm{~W} \cdot \mathrm{m}^{-1} \cdot \mathrm{K}^{-1}$ and a high compact geometry of finned-tube heat exchanger. Priority was given to the effect of optimized geometrical parameters (tube diameter; tube pitch; fin pitch and fin thickness) on the compactness, mass, heat exchange duty, and air side pressure drop. Results were obtained using numerical and nodal models allowing the identification of global performance of HXs. These models were validated with experimental data obtained for metallic HX ( $\mathbf{B}_{\text {com }}$ and $\mathbf{B}_{\text {cla }}$ ) then the compact polymer HXs were compared to these HXs.

\section{Numerical model}

The identification of overall performance was divided on two steps; the first one consisted on determining the heat thermal coefficient ' $\mathbf{U}$ ' and ' $\Delta \mathbf{P}$ ' on a single pattern and the second one was the calculation of the heat exchange duty ' $\mathbf{q}_{\mathbf{H X}}$ ' on the complete HX. To accomplish the first step, a numerical model was created using the commercial CFD software StarCCM+. After identification of representative pattern, boundaries conditions, physical model and mesh criteria this model was validated by comparing the results obtained on a metallic geometry ( $\left.\mathbf{M}_{\mathbf{c o m}}\right)$ with the experimental data obtained by Wang [15] 


\subsection{Geometry}

The study considered a multi row continuous finned-tube HX (figure 1). Water flows inside the tubes, and air between the fins and around the tubes. The heat exchanger matrix volume was considered to be: $\left(L_{x}, L_{y}, L_{z}\right)$ (figure 1a). In this study tube diameter varied from $11.7 \mathrm{~mm}$ to $2.5 \mathrm{~mm}$ and tube pitch from $30 \mathrm{~mm}$ to $9 \mathrm{~mm}$. A reference geometry ' $\mathbf{M}_{\text {com }}$ ' made of aluminum, having a matrix volume equal to $(200,110,240) \mathrm{mm}^{3}$ and the following dimensions (figure $1 \mathrm{~b}$ ): $\mathrm{D}=7.5 \mathrm{~mm} \mathrm{Pt}=18 \mathrm{~mm} \mathrm{Pf}=1.3 \mathrm{~mm} \mathrm{Ft}=0.1 \mathrm{~mm}$ and 6 rows of tubes, was also considered. This geometric parameters resulted from a typical compact heat exchanger made out of aluminum (for tube and fins). It can be founded in HVAC applications likes cooling and heating coils, finned coil heat exchangers, finned Pack Heat Exchanger, condenser coils, radiators, water-fluid coils, energy recovery systems.

This reference geometry ' $\mathbf{M}_{\text {com }}$ ' was used as a reference case and to validate the CFD models by comparing numerical results to experimental data obtained by Wang and Chi [15] (§ 2.5).

a)

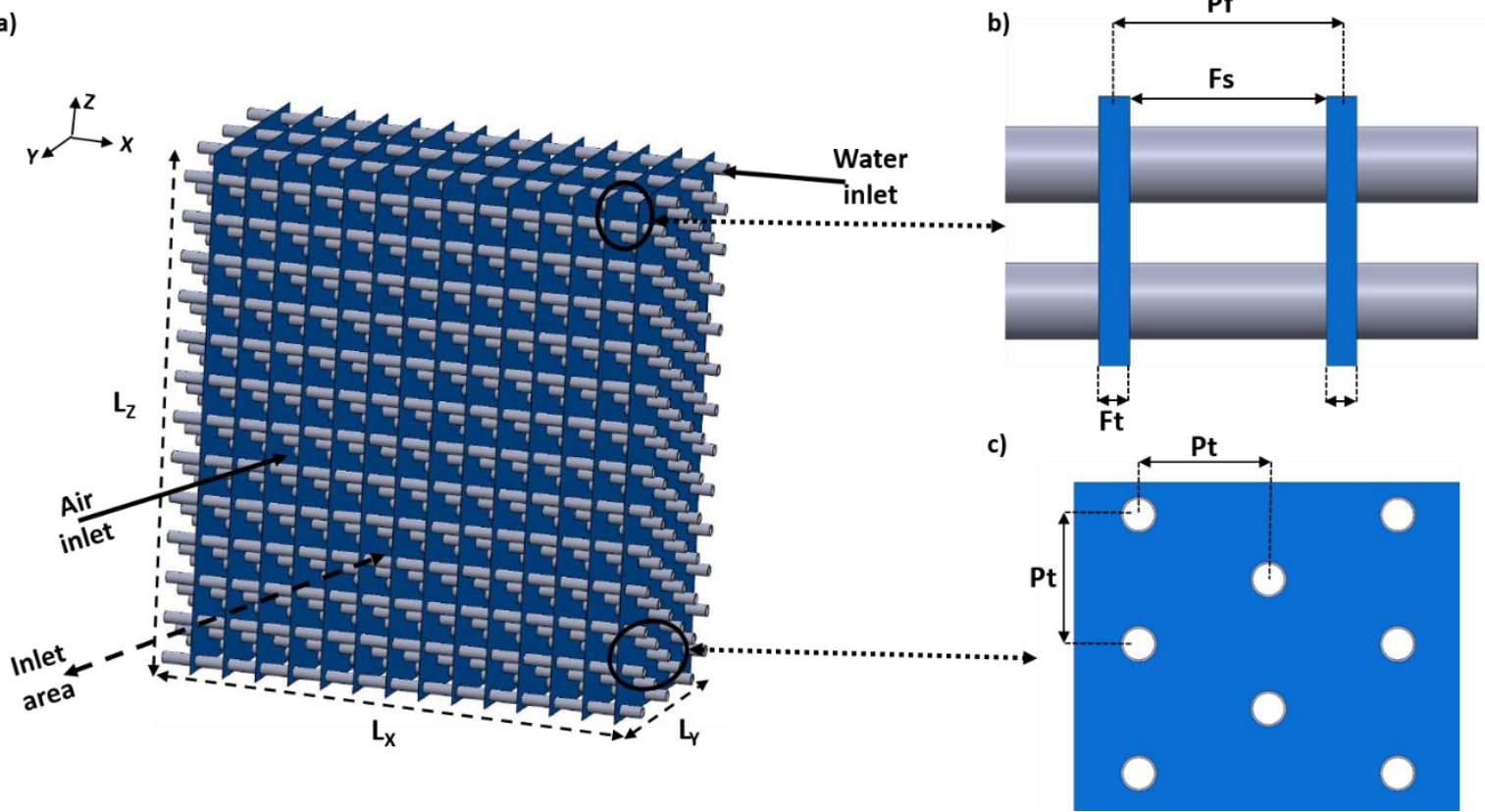

Figure 1: heat exchanger matrix a); details of $\mathrm{HX}$ up view b); side view c) 
a)

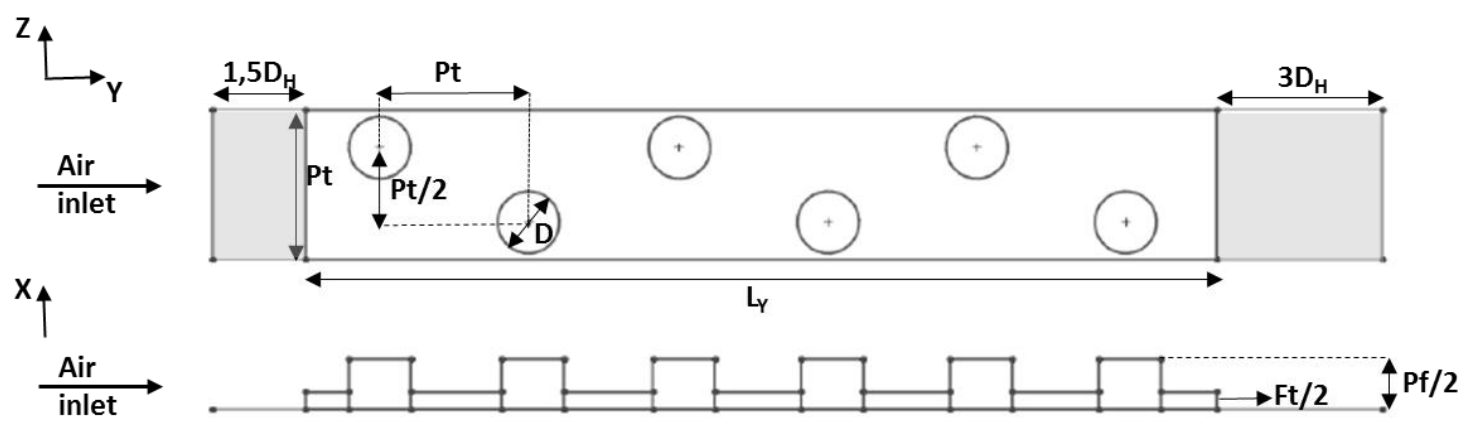

b)

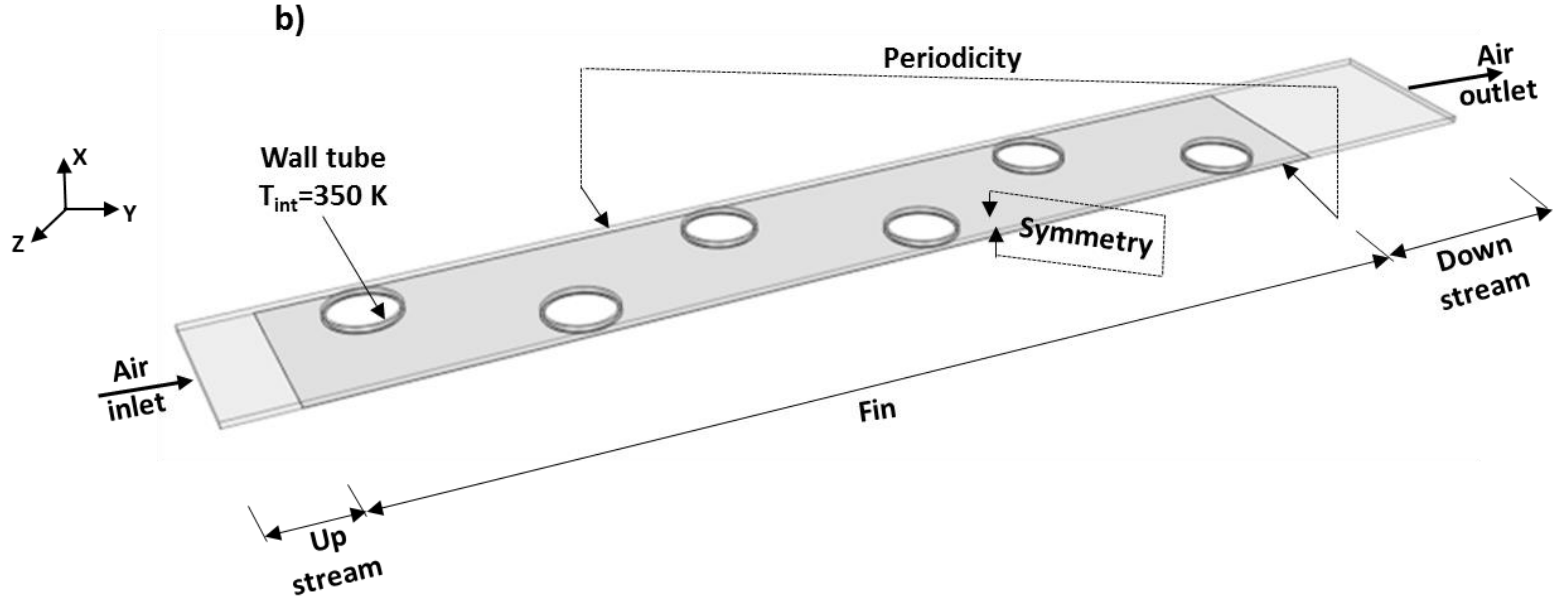

Figure 2: 6 rows finned-tube $\mathrm{HX}$ model a) computational domain b) boundary conditions

\subsection{Boundary conditions and thermo-physical properties}

To simplify the computational tasks, a representative element was considered (figure 2a) with the following assumptions (figure $2 b$ ):

- Symmetrical horizontal lower side plan of the fins: only one half thickness of fin is considered,

- Symmetrical horizontal upper side plan of the fins: only one half-step fin pitch is considered,

- Periodic boundary conditions applied on lateral surfaces: the development of an unsteady flow downstream the tubes for certain Reynolds numbers imposes the use of lateral periodicity conditions with the study of two tubes without symmetry conditions.

The geometry contains two zones upstream and downstream the fin to:

- Maintain the conditions on the leading edge upstream of the fin,

- Stabilize the flow after the wake zone downstream of the tube.

Tube thickness was fixed to $0.3 \mathrm{~mm}$. The air inlet temperature was set to $300 \mathrm{~K}$ with Reynolds number $\left(\mathbf{R e}_{\mathbf{D}}\right)$ ranging from 573 to 3650 based on the tube diameter. The inside wall temperature of the tube is considered constant at $350 \mathrm{~K}$ ' $\mathbf{T}_{\mathbf{i n t}}$ ' (water flow was not computed); the working fluid (air side) was assumed to be incompressible thus the flow was laminar for Reynolds number lower than 1800 , and turbulent for higher ' $\mathbf{R e}_{\mathbf{D}}$ '. For turbulent cases, the conservation equations that model the flow and heat transfer were solved using $k \omega-S S T$ turbulence model of Menter [14]. The choice of this turbulence model was guided by previous works which proved its suitability for this type of HX [15] [16]. Furthermore, the flow was steady except for certain ' $\mathbf{R e}_{\mathbf{p}}$ ' and fin-pitch $\left(\mathbf{R e}_{\mathbf{D}} \geq 750\right.$ and $\left.\mathbf{F p} \geq 2 \mathrm{~mm}\right)$ where unsteadiness phenomena were detected downstream the tubes. The thermo-physical properties were set as constant: density of $1.18 \mathrm{~kg} \cdot \mathrm{m}^{-3}$, thermal capacity of $1007.62 \mathrm{~J} \cdot \mathrm{Kg}^{-1}$, dynamic viscosity of $1.85 \cdot 10^{-5} \mathrm{~Pa}$.s and thermal conductivity was equal to $0.026 \mathrm{~W} \cdot \mathrm{m}^{-1} \cdot \mathrm{K}^{-1}$.

The air heat exchange coefficient $\left(\mathbf{U}_{\mathbf{a}}\right)$ was computed after solving the Navier-Stokes equations with these boundary's conditions, physicals properties, and turbulence models using the commercial CFD software StarCCM+. 


\subsection{Convergence criteria}

The convergence of the numerical CFD simulations was verified by monitoring the residuals evolution while solving iteratively the conservation equations. A computation was considered converged when the residuals became lower than $10^{-4}$ for the continuity and momentum equations, and lower than $10^{-6}$ for the energy equation. In addition to these residuals, the difference between heat duty wall side (fin and tubes) and air side becoming less than $0.3 \%$ was considered [17]. Considering that the system was adiabatic, the air heat duty evacuated by walls was recuperated by the air (Eq.1).

$\mathrm{q}_{\mathrm{fin}}+\sum_{\mathrm{i}=1}^{\mathrm{n}} \mathrm{q}_{\text {tube,i }}=\dot{\mathrm{m}}_{\mathrm{a}} \mathrm{Cp}_{\mathrm{a}}\left(\mathrm{T}_{\mathrm{a}, \text { out }}-\mathrm{T}_{\mathrm{a}, \text { in }}\right)$

For the unsteady cases, a periodic vortex shedding flow was found downstream the tubes. For that reason, a mean function (as a spatial-temporal average 'terminology StarCCM+') was created to calculate the temporal average of pressure drop and output temperature, and then the overall global performance indicator. The time step was calculated based on the Strouhal number as in previous published paper (St) [17]. Time step was considered as $1 / 20$ of a period (Eq. 2):

time step $=\frac{D_{\text {ext }}}{20 . \text { St. } v_{a}}$

For the considered Reynold range in this paper, 'St' was equal to 0.2 [17].

The thermal balance equation was given by (Eq. 3):

$\mathbf{q}_{\text {fin }}+\sum_{\mathrm{i}=1}^{\mathrm{n}} \mathbf{q}_{\text {tube, }}=\dot{\mathbf{m}}_{\mathrm{a}} \mathbf{C} \mathbf{p}_{\mathbf{a}}\left(\mathbf{T}_{\text {mean,a,out }}-\mathbf{T}_{\mathrm{a}, \mathrm{in}}\right)$

And

$\mathrm{T}_{\text {mean,a,out }}$ was the outlet average temperature after 5 periods for unsteadiness establishment

\subsection{Mesh sensitivity analysis}

To ensure a good compromise between calculation time, used memory and results accuracy, a study of the mesh sensibility was carried out. Four mesh configurations were analyzed for the reference case with air inlet velocity equal to $1 \mathrm{~m} \cdot \mathrm{s}^{-1}$, each mesh containing 3 cellular dimensions: for the fin, for the fluid and for the tube (table 1). A suitable mesh allowed to pick up the physical phenomenon prevailing inside of the element of the HX. The thickness of the tube was divided into 4 to 7 cells, and the junction between tube and fin contains 4 to 7 cells in width and 2 to 6 cells in height. As for the mesh of the air, it was refined (figures 3a and 3b) to detect the physical phenomena that took place near the leading fin edge and around tube-fluid interface (as the development of boundary layer and horseshoe vortex). Figure $3 \mathrm{a}$ and $\mathrm{b}$ show these refinements in the crucial regions. This process of mesh sensitivity analysis used a refinement factor maintained at 1.3 as required in the process defined by Divison and al [18].

In the present study, the mesh refinement was assessed by the heat exchange duty, pressure drop and air heat exchange coefficient ' $\mathbf{U}_{\mathbf{a}}$ ' which were of major interest in the present study. $\mathbf{U}_{\mathbf{a}}$ was calculated using the following relations (Eq. 4):

$\mathbf{U}_{\mathbf{a}}=\frac{\mathbf{q}_{\mathbf{a}}}{\mathrm{S}_{\mathbf{a}} \Delta \mathbf{T}_{\mathrm{LM}}}$

Where $\Delta \mathrm{T}_{\mathrm{LM}}$ was the logarithmic temperature difference (Eq. 5):

$$
\Delta \mathbf{T}_{L M}=\frac{\left(T_{\text {tube,int }}-T_{\text {,in }}\right)-\left(T_{\text {tube,int }}-T_{a, \text { out }}\right)}{\ln \left(\frac{T_{\text {tube, int }}-T_{a, \text { in }}}{T_{\text {tube, int }}-T_{a, \text { out }}}\right)}
$$

The results (table 1) show that the relative error between the 3 configurations and the one with the maximum number of cells ( 4.5 millions) was lower than $0.15 \%$ for the heat exchange duty, but higher for pressure drops and air heat exchange coefficient $\mathbf{U}_{\text {air. }}$. In consequence Mesh 3 (good comprise between calculation time and accuracy) was chosen for all the further computations.

Table 1: Mesh sensitivity analysis

$\begin{array}{llll}\text { Mesh } & \text { Max element size } & \text { Total } & \text { Relative error }\end{array}$




\begin{tabular}{cccccccc} 
& Fin $(\mathrm{mm})$ & Air $(\mathrm{mm})$ & Tube $(\mathrm{mm})$ & $\begin{array}{c}\text { number of } \\
\text { cell } 10^{6}\end{array}$ & $\mathrm{q}_{\mathrm{a}}(\%)$ & $\mathrm{U}_{\mathrm{a}}(\%)$ & ??P $(\%)$ \\
\hline Mesh 1 & 0.875 & 0.375 & 0.05 & 4.5 & - & - & 3.8 \\
Mesh 2 & 0.9 & 0.425 & 0.055 & 3.5 & 0.06 & 2.8 \\
Mesh 3 & 1 & 0.5 & 0.06 & 2.4 & 0.09 & 5.0 & 3.3 \\
Mesh 4 & 1.25 & 0.75 & 0.075 & 1.4 & 0.15 & 16.3 & 4.8 \\
\hline
\end{tabular}

a)

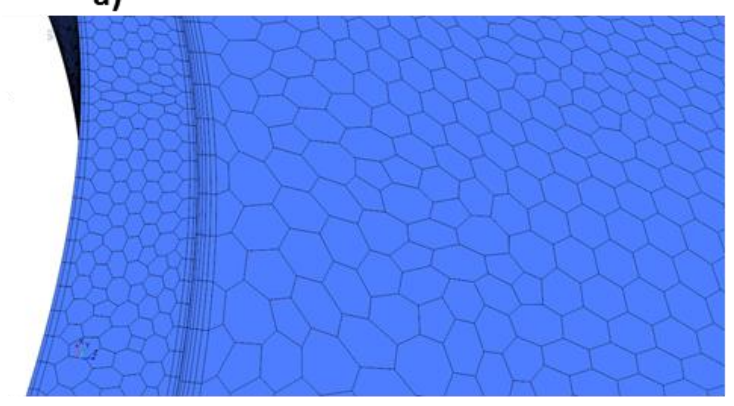

b)

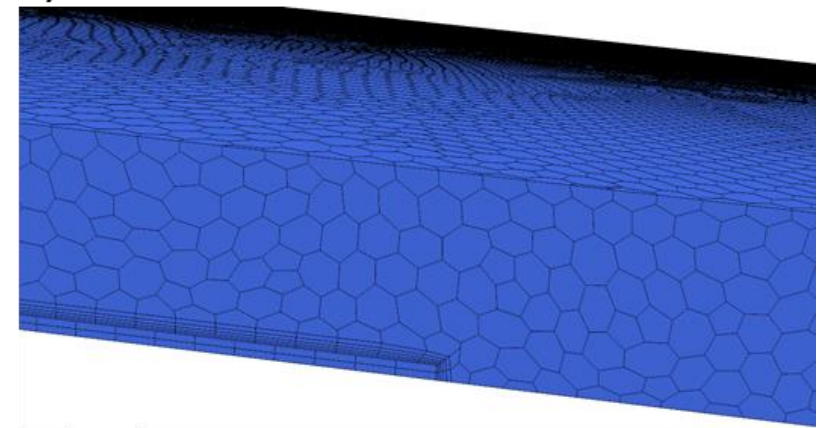

Figure 3: Detail of the mesh near the tube-fluid a) and fin-fluid interfaces b)

\subsection{Validation of the numerical model}

To validate the numerical model, comparisons were elaborated for the Colburn factors $\mathrm{j}$ and friction $\mathrm{f}$, with the correlations based on experimental previously published in the open literature for classical metallic HX [19]. These correlations are valid beyond certain range of dimensions and a maximal number of tubes rows ( 6 rows of tubes). In this direction, the reference geometry presented in paragraph 2-1 was analyzed (reference case ' $\mathbf{M}_{\text {com }}$ ') using our numerical model with the chosen mesh (Mesh 3). The experimental data of $j$ and $f$ coefficients [15] and the $\mathrm{j}$ and $\mathrm{f}$ coefficients resulting from CFD calculation were founded to be similar. The difference range in function of $\mathbf{R e}_{\mathbf{D}}$ was between 5 and $15 \%$ (figure 4). Thus the CFD calculation (with its geometrical parameters, mesh optimization, convergence criteria) could be considered as validated by Wang results [15].

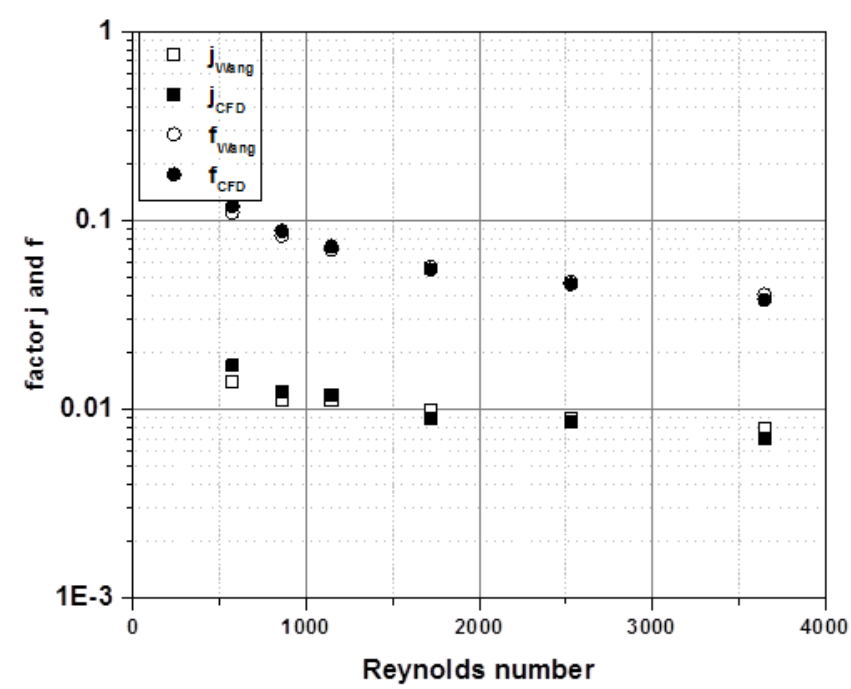

Figure 4: Factors $j$ and f function of Reynold number

\section{Global performance analysis of a liquid-gas heat exchanger}

The numerical model (CFD) explained previously served to calculate the air side performance ' $\mathbf{U}_{\mathbf{a}}$ ' of a single representative pattern, knowing that the identification of global heat exchange duty ' $\mathbf{q}_{\mathbf{H x}}$ ' imposed the use of a nodal model that models the whole heat transfer process (waterside convection, airside convection , conduction) 
for the totality of HX (figure 5). A scheme of the nodal model principle is present in figure 6. In general, for a metallic HX, the global heat exchange duty depends on the thermal resistance of air (for about $87 \%$ ), of liquid, of tubes and of contact thermal resistance between tubes and fins (for about $10 \%$ ) [20][21]. This later contribution cannot be neglected in the calculation. It was directly due to the manufacturing process of the metallic HX based on the assembly (by mechanical expansion or welding) of tubes and fins. It leads to formation of an imperfect interface with a significant contact resistance. In the case of polymer HX, this drawback could be limited by the simultaneous formation and assembly (during plastic processing) of the different components in the melt state. So, the contact resistance between tubes and fins could be neglected. But, on the other hand, due to the low thermal conductivity of the polymer, the contribution of the thermal resistance of the wall would be higher. As a consequence, for the calculation of the global heat performance of the HXs, all these thermal resistances (air resistance, water resistance, tube wall resistance and contact resistance) would be considered in one equation (equation 6):

$\mathrm{U}_{\mathrm{g}}=\frac{1}{\mathrm{r}_{\mathrm{a}}+\mathrm{r}_{\text {cont }}+\mathrm{r}_{\mathrm{w}}+\mathrm{r}_{\mathrm{t}}}$

The heat exchange coefficient and the outlet temperature on the air side were determined using the CFD model (see paragraph 2), the contact thermal resistance was taken into consideration in the simulations for the metallic HX and set to zero for polymer HX. On the water side, the geometry was simple and the heat exchange coefficient could be estimated using the classic correlation governing a flow through a cylindrical tube. Thus the HX global heat performance could be calculated by combining the numerical and analytical models in a nodal system using equation 7 while the thermal performance was determined for each node and then for the complete HX.

$\mathrm{U}_{\mathrm{g}} \mathrm{S}=\frac{1}{\frac{1}{\mathrm{~S}_{\mathrm{a}} \mathrm{U}_{\mathrm{a}}}+\frac{1}{\mathrm{~S}_{\mathrm{eau} U_{\mathrm{w}}}}+\frac{\ln \left(\mathrm{R}_{\text {ext }} / \mathrm{R}_{\text {int }}\right)}{\mathrm{k} 2 \pi \times \mathrm{l}}}$

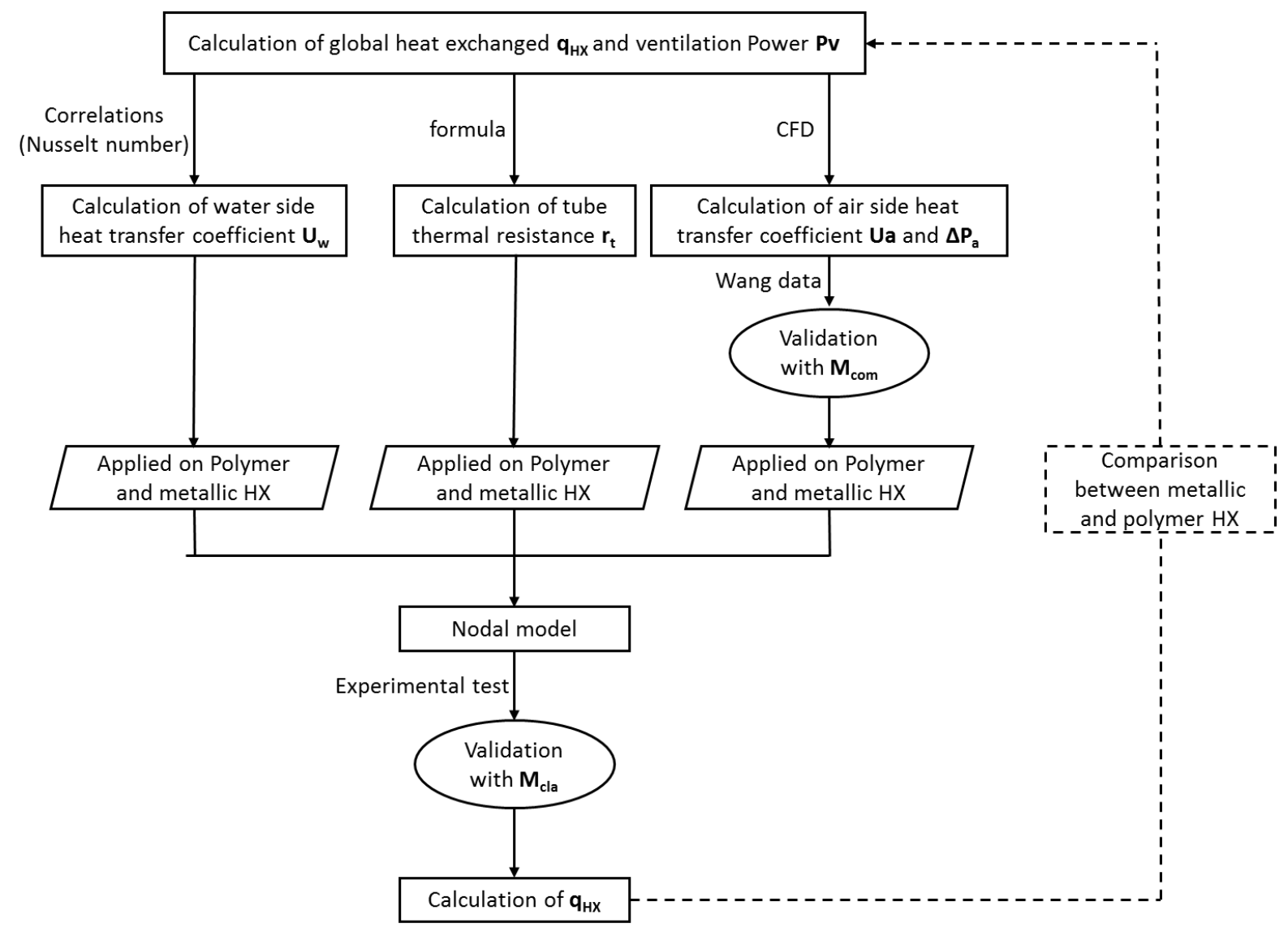

Figure 5 : methodology of overall performance calculation 


\subsection{Nodal Model}

In a HX, the heat duty evacuated by the hot fluid is totally or partially recovered by the cold one. In the present study the hot fluid was water and cold one was air. Assuming that the global system is adiabatic, the heat exchange duty was calculated using the system of equations 8 and equation 9 .

$$
\begin{gathered}
\left\{\begin{array}{cc}
\mathrm{q}_{\mathrm{HX}}=\dot{\mathrm{m}}_{\mathrm{a}} \mathrm{Cp}_{\mathrm{a}}\left(\mathrm{T}_{\mathrm{a}-\text { out }}-\mathrm{T}_{\mathrm{a}-\text { in }}\right) & a \\
\mathrm{q}_{\mathrm{HX}}=\dot{\mathrm{m}}_{\mathrm{w}} \mathrm{Cp}_{\mathrm{w}}\left(\mathrm{T}_{\mathrm{w}-\text { in }}-\mathrm{T}_{\mathrm{w}-\text { out }}\right) & b \\
\mathrm{q}_{\mathrm{HX}}=\mathrm{U}_{\mathrm{g}} \mathrm{S} \Delta \mathrm{T}_{\mathrm{lm}} & c
\end{array}\right. \\
\text { Where } \Delta \mathbf{T}_{\mathrm{LM}}=\frac{\left(\mathbf{T}_{\mathbf{w}, \text { in }}-\mathbf{T}_{\mathbf{a}, \text { in }}\right)-\left(\mathbf{T}_{\mathbf{w}, \text { out }}-\mathbf{T}_{\mathbf{a}, \text { out }}\right)}{\ln \left(\frac{\mathrm{T}_{\mathbf{w}, \text { in }}-\mathrm{T}_{\mathbf{a}, \text { in }}}{\mathbf{T}_{\mathbf{w}, \text { out }}-\mathbf{T}_{\mathbf{a}, \text { out }}}\right)}
\end{gathered}
$$

So, the system to be solved was a system of three equations (8a, $8 b$ and $8 c$ ) and three unknown values: $\mathbf{q}_{\mathbf{H x}}$, $\mathbf{T}_{\mathrm{w}, \text { out }}$ et $\mathbf{T}_{\mathrm{a}, \text { out }}$, whose solution was (Eq. 10):

$\mathbf{q}_{\mathbf{H X}}=\frac{\mathbf{T}_{\mathbf{i n}, \mathrm{w}}-\mathbf{T}_{\mathbf{i n}, \mathbf{a}}}{\mathbf{C}}-\frac{\mathbf{T}_{\mathbf{i n}, \mathbf{w}}-\mathbf{T}_{\mathbf{i n}, \mathbf{a}}}{\mathrm{Ce}^{\mathrm{UgSC}}}$
with $\mathrm{C}=\frac{1}{\dot{\mathrm{m}}_{\mathrm{w}} \mathrm{Cp}}+\frac{1}{\dot{\mathrm{m}}_{\mathrm{a}} \mathrm{Cp} \mathrm{a}}$

This system was solved at each node of the discretized geometrical scheme (Figure 6a), where the heat exchanger had been divided into simple elements (nodes) composed of the air channel between two consecutive fins and the tube parts intercepting this air channel (figure $6 \mathrm{~b}$ ).

With

$\mathrm{i}$ : index in the air flow direction ( $\mathrm{i}=1$ to number of row)

$\mathrm{j}$ : index in the tube direction ( $\mathrm{j}=1$ to number of fins)

For a given node, the air inlet temperature and water inlet temperature were equal to the air outlet temperature and water outlet temperature of the previous node, respectively. The same principle was followed for the air and water velocities. For the first node, the inlet air, water temperatures and velocity are usually known values.

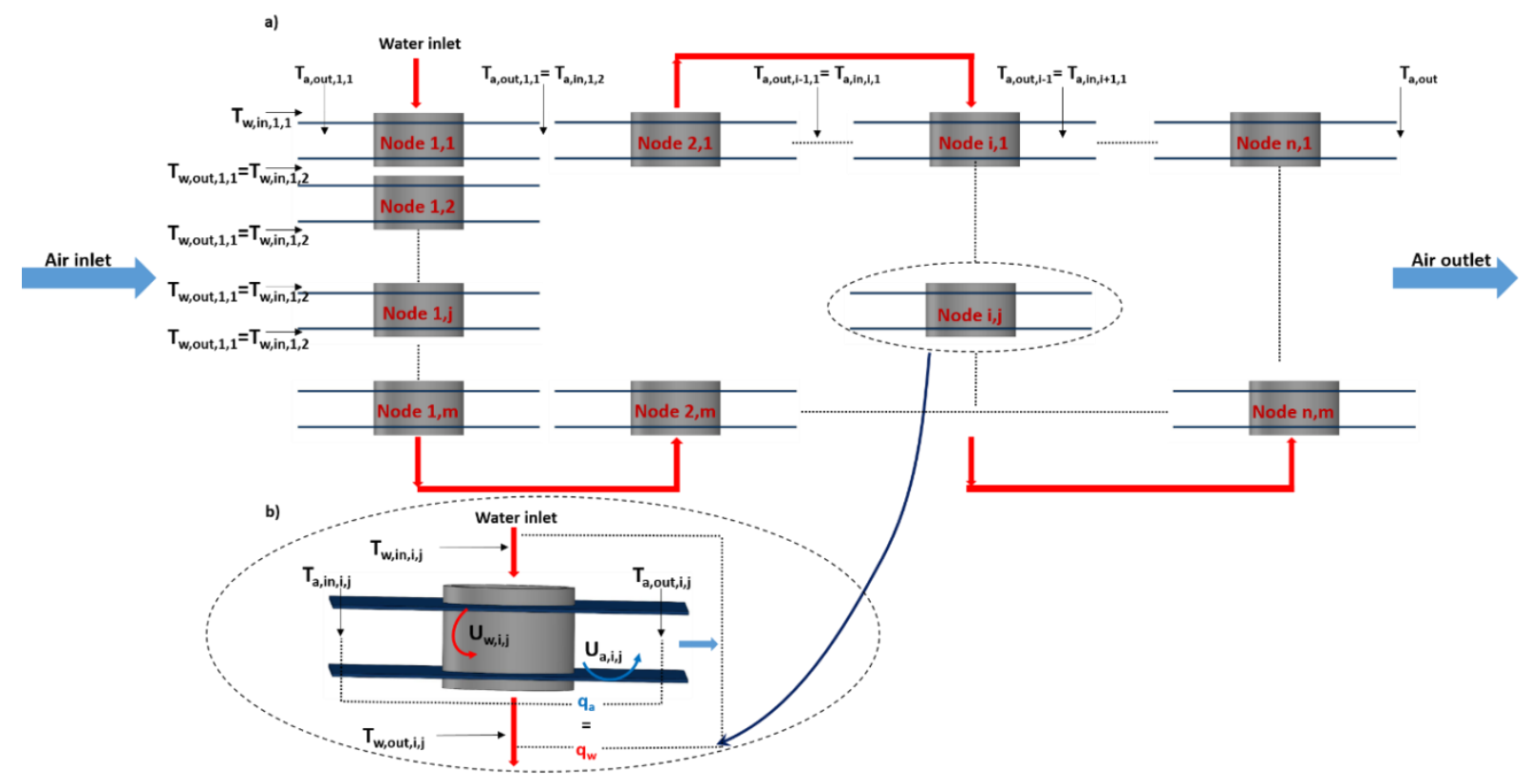

Figure 6: heat balance a) nodal model b) single node

a) Determination of water side heat transfer coefficient ' $\mathbf{U}_{\underline{\mathbf{w}}}$ '

Water side heat transfer coefficient ' $\mathbf{U}_{\mathbf{w}}$ ' was calculated based on Nusselt number using well known correlations (Eq $11 ; 12)$ governing a flow inside a cylindrical tube. These correlations were function of water velocity and 
tube diameter, hence $\mathbf{U}_{\mathbf{w}}$ was constant (for a trifling variation of thermo-physics properties), whatever the rank and number of the node were.

$\mathrm{Nu}_{\mathrm{w}}=0.023 \operatorname{Re}_{\mathrm{w}}^{0.8} \operatorname{Pr}_{\mathrm{w}}^{0.3}$
$\mathbf{U}_{\mathbf{w}}=\frac{\mathrm{Nu}_{\mathbf{w}} \cdot \mathbf{k}_{\mathbf{w}}}{\mathbf{D}_{\text {int }}}$

b) Determination of air side heat transfer coefficient ' $\mathbf{U}_{\underline{a}}$ '

Air side heat transfer coefficient was calculated based on the numerical simulation. It varied with nodes following the air flow direction but remained the same in the tube direction (for the same tube row $\mathbf{m} \mathbf{C} \mathbf{p} \Delta \mathbf{T}$ is the same). Relation 13 is applied on each node to obtain the air side heat exchange coefficient $\mathbf{U}_{\mathrm{a}, \mathrm{i}, \mathrm{j}}$.

$\mathbf{U}_{\mathrm{a}, \mathrm{i}, \mathrm{j}}=\frac{\mathbf{q}_{\mathbf{a}, \mathbf{i}, \mathbf{j}}}{s_{\mathbf{a}} \times \Delta \Delta \mathbf{T}_{\mathrm{LM}, \mathrm{i}, \mathrm{j}}}$

With s: area of single pattern

c) Determination of global heat duty

Global heat duty was calculated by replacing the water and air inlet temperature, $\mathbf{U}_{\mathbf{a}}$ and $\mathbf{U}_{\mathbf{w}}$ in equation 10 , then this equation was successively solved while using the air and water inlet temperature in the next node equal to

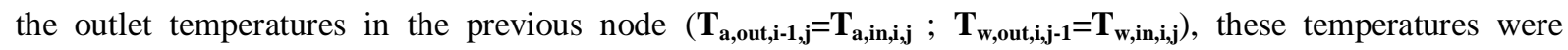
calculated according to equations (8a and $8 \mathrm{~b}$ ). The global heat duty of HX was (equation 14):

$\mathbf{q}_{\mathbf{H X}}=\sum_{\mathrm{i}=1}^{\mathrm{n}} \sum_{\mathbf{j}=\mathbf{1}}^{\mathrm{m}} \mathbf{q}_{\mathrm{HX}, \mathbf{i}, \mathrm{j}}$

\subsection{Validation of nodal model}

The experimental validation of the nodal model presented in previous was carried out using a specific experimental test module (figure 7a) developed at IMT Lille Douai (Energy Engineering Department). This bench is able to determine the overall heat performance of real finned-tube heat exchanger with air inlet section of $240 \times 200 \mathrm{~mm}^{2}$, this evaluation is based on a measurement of the flow, with flow meter and of the inlet and outlet temperatures with thermocouples and air pressure at the inlet and outlet of the HX prototype. This experimental set-up contains 3 main zones: (i) Plenum zone contain a hot battery in order to maintain the air inlet temperature constant; a plenum box where the air is guided and slowed by honeycomb structures; convergent evolution in order to accelerate the flow before the upstream zone. (ii) Test zone, where the HX is located with thermocouples upstream and downstream in order to evaluate the global heat performance. (iii) Suction zone contains the flow meter and the fan. This experimental test was carried out for a five row typical metallic fin and tube heat exchanger ' $\mathbf{M}_{\mathrm{cla}}$ '. Tubes were made of copper and fin material is aluminum. This battery had the following geometric parameters: $\mathbf{D}_{\text {ext }}=11.7 \mathrm{~mm} \mathbf{D}_{\text {int }}=11.35 \mathrm{~mm}, \mathbf{P t}=30 \mathrm{~mm} \mathbf{F}_{\mathbf{t}}=0.135 \mathrm{~mm}$ and $\mathbf{F} \mathbf{p}=3 \mathrm{~mm}$ (figure 7b) [22] with external dimensions equal to $:\left(L_{x}, L_{y}, L_{z}\right)=(200,180,240) \mathrm{mm}^{3}$. The Reynolds number (air side) range considered had been chosen between 1750 and 4420 and water velocity was fixed as $1.5 \mathrm{~m}^{-1}$ (table 2). The same cases with the same heat exchanger were evaluated with numerical and nodal model. It should also be noted that in this type of HX (metallic HX) a thermal resistance was developed between tube and fin, which was taken into consideration in the simulations (it could be settle with a specific terminology in StarCCM+). It was considered constant and equal to $1.5 \times 10^{-4} \mathrm{~m}^{2} \cdot \mathrm{K}^{-1} \cdot \mathrm{W}^{-1}$ [23]. The difference between experimental and numerical values was lower than $10 \%$ (Figure 8 ) and the nodal model could be considered as validated.

Table 2: experimental data

\begin{tabular}{ccccc}
\hline $\mathrm{v}_{\mathrm{w}}\left(\mathrm{m} . \mathrm{s}^{-1}\right)$ & $\mathrm{v}_{\text {air }}\left(\mathrm{m} . \mathrm{s}^{-1}\right)$ & $\mathrm{q}_{\mathrm{HX}}(\mathrm{kW})$ & $\mathrm{T}_{\text {air,in }}(\mathrm{K})$ & $\mathrm{T}_{\mathrm{w}, \text { in }}(\mathrm{K})$ \\
\hline \multirow{3}{*}{1.5} & 1.61 & 2.1 & 297.67 & 338.39 \\
& 2.13 & 2.5 & 295.22 & 338.39 \\
& 2.96 & 3.14 & 297.15 & 338.35 \\
& 4.07 & 3.75 & 296.13 & 338.33 \\
\hline
\end{tabular}




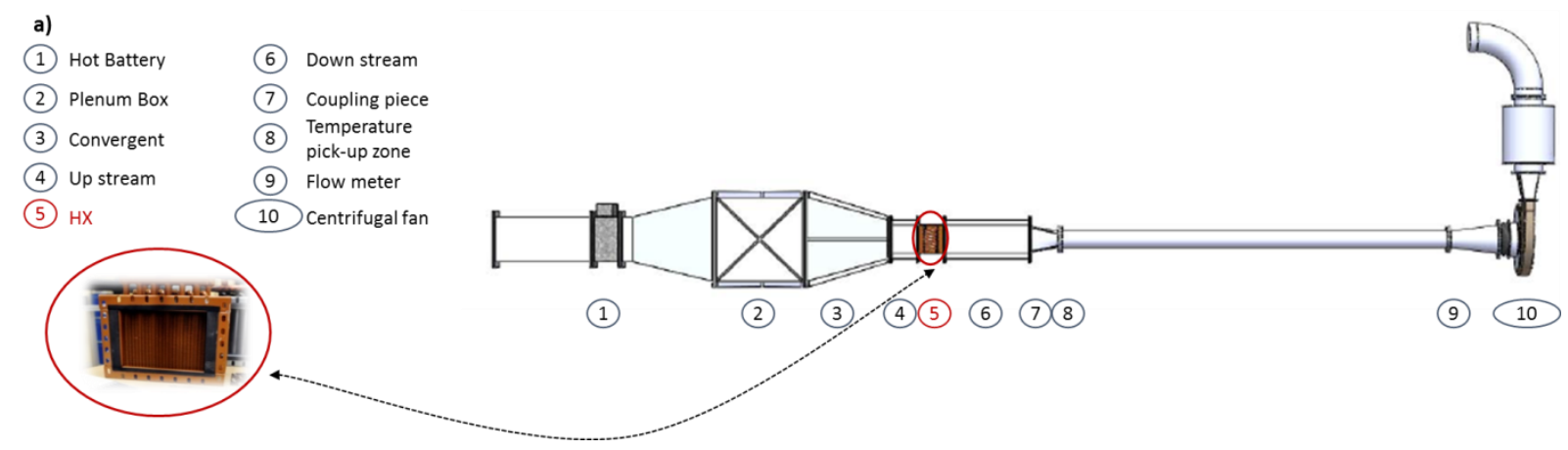

Figure 7: a) experimental test module schematic view b) experimental test module real view c) metal HX $B_{\text {ref2 }}$

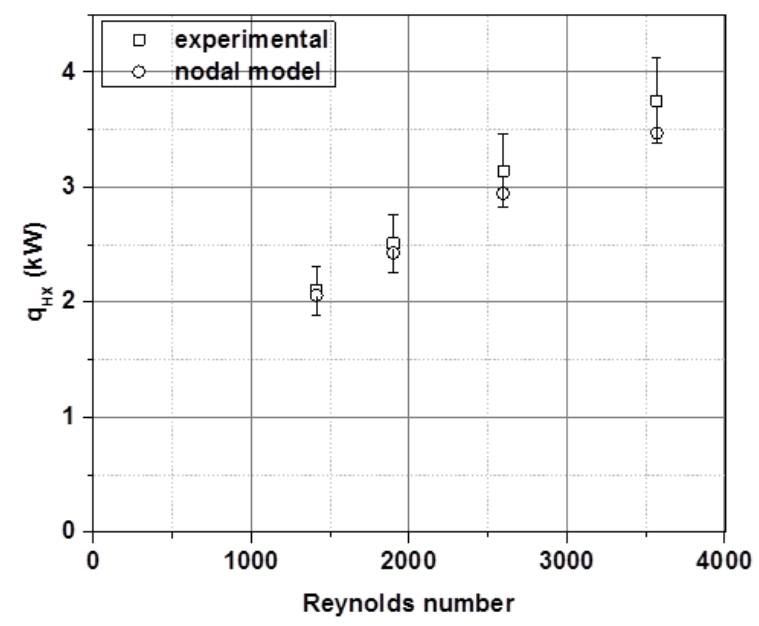

Figure 8: comparison between analytical and experimental heat exchange duty

\section{Definition of polymer heat exchanger}

The study of polymer heat exchangers depends mainly on their geometrical parameters and the thermal properties of their constitutive material. In this context, the configurations of polymer heat exchangers as well as thermal properties of the composite considered were developed in this section.

\subsection{Geometries and configurations}

In finned-tube HX, heat transfer depends on the conjugate conduction/convection. The thermal flux is indeed a function of both the thermal conductivity of solid parts and the convection heat coefficient between the gas and the surrounding walls which depends on the shape and dimensions of tubes and fins. In this context two geometries (see table 3) were considered using a filled polymer. At constant frontal area and external volume (identical than the $\left.\mathbf{M}_{\mathbf{c o m}}\right):\left(\mathbf{L}_{\mathbf{x}}, \mathbf{L}_{\mathbf{y}}, \mathbf{L}_{\mathbf{z}}\right)=(200,110,240) \mathrm{mm}^{3}$. They presented smaller tubes diameter and tubepitch than metallic heat exchanger. These geometrical modifications were thought to induce a double positive effect: (i) increase in the heat exchange surface and (ii) improve in the heat flux [24]. In order to assure the compromise between the heat flux transmitted via conduction between the tubes, and a reasonable pressure loss the ratio of tube diameter and tube pitch ' $\mathbf{D}_{\text {ext }} / \mathbf{P t}$ ' were chosen between 0.27 and 0.37 [25]. Finally, two configurations ( $\mathrm{a}$ and $\mathrm{b}$ ) were considered for each geometry corresponding to two fin arrangements:

- Configurations 'a' $\mathbf{F t}=0.1 \mathrm{~mm}$ and $\mathbf{P f}=1.3 \mathrm{~mm}$ : they had the same fin thickness and fin pitch than the reference geometry ' $\mathbf{M}_{\mathbf{c o m}}$ ' ( $(2.1)$, and allowed to reduce the mass of HX while preserving the number of fins (fins presented about $80 \%$ of $\mathrm{HX}$ mass). 
- Configurations ' $b$ ' $\mathbf{F t}=0.25$ and $\mathbf{P f}=2 \mathrm{~mm}$ : they had a similar weight than the reference geometry ' $\mathrm{B}_{\text {ref1 }}$ ', but the fins thickness was larger. Following Gardner relations [18], the fin thickness has a positive effect on the fin efficiency and consequently on the overall thermal performance.

Table 3: geometric parameters

\begin{tabular}{lllllll}
\hline Geometry & $\begin{array}{l}\text { Row of } \\
\text { tube }\end{array}$ & $\mathrm{D}_{\text {ext }}(\mathrm{mm})$ & $\mathrm{Pt}_{\mathrm{lg}}(\mathrm{mm})$ & $\mathrm{Pt}_{\mathrm{tr}}(\mathrm{mm})$ & $\mathrm{Pf}(\mathrm{mm})$ & $\mathrm{Ft}(\mathrm{mm})$ \\
\hline $\mathrm{M}_{\mathrm{com}}$ & 6 & 7.5 & 18 & 18 & 1.3 & 0.1 \\
$\mathrm{M}_{\text {cla }}$ & 5 & 11.7 & 30 & 30 & 3 & 0.135 \\
\hline $\mathrm{P}_{1 \mathrm{a}}$ & 8 & 5 & 13.5 & 13.5 & 1.3 & 0.1 \\
$\mathrm{P}_{1 \mathrm{~b}}$ & 8 & 5 & 13.5 & 13.5 & 2 & 0.25 \\
$\mathrm{P}_{2 \mathrm{a}}$ & 12 & 2.5 & 9 & 9 & 1.3 & 0.1 \\
$\mathrm{P}_{2 \mathrm{~b}}$ & 12 & 2.5 & 9 & 9 & 2 & 0.25 \\
\hline
\end{tabular}

\subsection{Polymer properties}

In order to study the manufacturing of heat exchangers based on filled polymer, the commercial PA66 compound (PolyOne TT9200-5003 EC MID) was chosen as raw material. The thermal properties of this composite were analyzed with the aim to attain the expected performance of these types of heat exchangers. The composite matrix had a thermal conductivity ' $\mathrm{k}$ ' of $0.25 \mathrm{~W} \cdot \mathrm{m}^{-1} \cdot \mathrm{K}^{-1}$ and density of $1.6 \mathrm{~g} . \mathrm{cm}^{-3}$ but the addition of conductive fillers induced an anisotropic thermal behavior and an increase in the overall thermal conductivity [4]. Measures of thermal conductivity were made with Disks of $160 \mathrm{~mm}$ in diameter and 3 thickness steps of $(6,4 \mathrm{and} 2 \mathrm{~mm}$, figure 9a). they were injection moulded with the Arburg Allrounder 320A machine and the following parameters: the injection/mold temperature was $300^{\circ} \mathrm{C}$, the flow rate was $100 \mathrm{~mm} / \mathrm{sec}$, the holding pressure was 550 bars and the holding time was $8 \mathrm{sec}$. Using these disks, samples of 2, 4 and $6 \mathrm{~mm}$ was prepared (figure 9b), their radial and axial thermal conductivity were measured using the hot disk method detailed in norms ISO 22007-2 [26] (figure 9c and d). The results are showed in table 4, and there were coherent with the data sheet given by the supplier (' $\mathbf{k}_{\mathrm{rad}}$ ' between 16 and $18 \mathrm{~W} \cdot \mathrm{m}^{-1} \cdot \mathrm{K}^{-1}$ and ' $\mathbf{k}_{\mathbf{a x}}$ ' between 2.2 and $4 \mathrm{~W} \cdot \mathrm{m}^{-1} \cdot \mathrm{K}^{-1}$ ). Thus an anisotropic thermal conductivity was considered into the simulations with $\mathbf{k}_{\text {rad }}$ of $17.2 \mathrm{~W} \cdot \mathrm{m}^{-1} \cdot \mathrm{K}^{-1}$ (for the fin) and $\mathbf{k}_{\mathbf{a x}}$ of $2.5 \mathrm{~W} \cdot \mathrm{m}^{-1} \cdot \mathrm{K}^{-1}$ (for the tubes).

Table 4: thermal properties of Polyamide 66 (PolyOne)

\begin{tabular}{lccc}
\hline Polyone - Polyamide 66 & $2 \mathrm{~mm}$ & $4 \mathrm{~mm}$ & $6 \mathrm{~mm}$ \\
\hline $\mathrm{k}_{\mathrm{rad}}\left(\mathrm{W} \cdot \mathrm{m}^{-1} \cdot \mathrm{K}^{-1}\right)$ & 17.8 & 16.89 & 16.37 \\
$\mathrm{k}_{\mathrm{ax}}\left(\mathrm{W} \cdot \mathrm{m}^{-1} \cdot \mathrm{K}^{-1}\right)$ & - & 2.4 & 3.3 \\
$\mathrm{Cp}\left(\mathrm{J} \cdot \mathrm{Kg}^{-1} \cdot \mathrm{K}^{-1}\right)$ & 1135 & 1135 & 1135 \\
\hline
\end{tabular}


a)

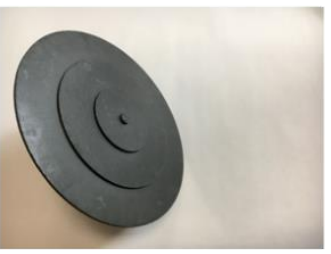

b)

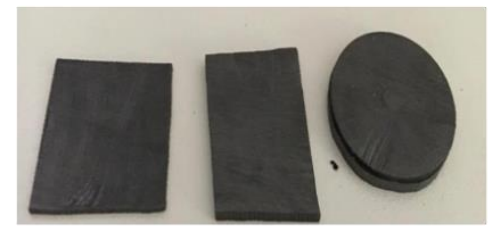

c) Specimen
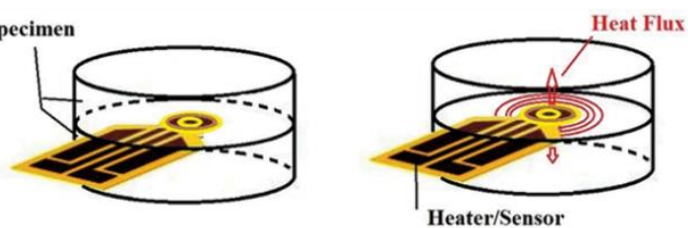

d)

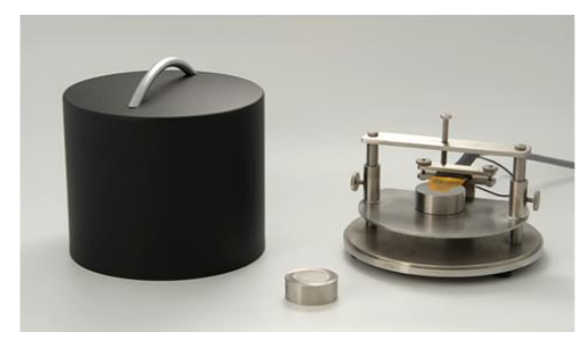

Figure 9: a) disk of commercial PA66; b) samples of 3 thicknesses ( $2 \mathrm{~mm}, 4 \mathrm{~mm}$ and $6 \mathrm{~mm}$ ); c) hot disk schematic view; d) Hot disk real view

\section{Results and discussions}

In order to compare metallic with compact polymer HXs, two metallic HXs were considered as reference (table 5):

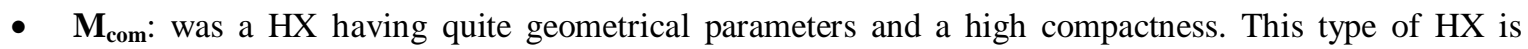
normally used for a HVAC applications with a high thermal performance requirement such as finned pack coils for compact HVAC unit (section 2), knowing that the operation cost directly related to the pressure drop air side in this type of battery is very high.

- $\quad \mathbf{M}_{\text {cla }}$ : was a classic battery (section 3) which is frequently founded in the trade and it is used in heat and air conditioning applications or heat recovery system with a lower request of heat exchanged duty.

The global performances were determined using the CFD and nodal model explained in sections 2 and 3 . The numerical simulation was used to calculate the air side heat transfer coefficient and air side pressure drops and the nodal model to evaluate the global heat exchange duty. The thermal contact resistance for metallic batteries, was considered equal to $1.1 \times 10^{-4} \mathrm{~m}^{2} . \mathrm{K} . \mathrm{W}^{-1}$ and $1.5 \times 10^{-4} \mathrm{~m}^{2} \cdot \mathrm{K} . \mathrm{W}^{-1}$ respectively for $\mathbf{M}_{\text {com }}$ and $\mathbf{M}_{\text {cla }}(10 \%$ of global thermal resistance) [23] [27]. The air and water inlet temperatures in all cases were fixed to $300 \mathrm{~K}$ and $350 \mathrm{~K}$, four values of air inlet velocity were studied: $1,2,3$ and $4 \mathrm{~m} \cdot \mathrm{s}^{-1}$ and the water velocity inside the tube was fixed to $1.5 \mathrm{~m} \cdot \mathrm{s}^{-1}$.

Table 5: specification of batteries

\begin{tabular}{cccccc}
\hline Geometry & $\begin{array}{c}\text { External } \\
\text { dimensions } \\
\left(\mathrm{mm}^{3}\right)\end{array}$ & $\mathrm{S}_{\mathrm{w}}\left(\mathrm{m}^{2}\right)$ & $\mathrm{S}_{\mathrm{a}}\left(\mathrm{m}^{2}\right)$ & $\begin{array}{c}\text { Compactness } \\
\left(\mathrm{m}^{2} / \mathrm{m}^{3}\right)\end{array}$ & $\begin{array}{c}\text { Mass } \\
(\mathrm{kg})\end{array}$ \\
\hline $\mathrm{M}_{\text {com }}$ & $200 \times 110 \times 240$ & 0.35 & 8.47 & 1604.35 & 1.25 \\
$\mathrm{M}_{\mathrm{cla}}$ & $200 \times 180 \times 240$ & 0.25 & 3.7 & 431.4 & 1.8 \\
$\mathrm{P}_{1 \mathrm{a}}$ & $200 \times 110 \times 240$ & 0.4 & 8.55 & 1619.41 & 0.74 \\
$\mathrm{P}_{1 \mathrm{~b}}$ & $200 \times 110 \times 240$ & 0.4 & 5.68 & 1076.17 & 1.25 \\
$\mathrm{P}_{2 \mathrm{a}}$ & $200 \times 110 \times 240$ & 0.39 & 8.61 & 1628.25 & 0.68 \\
$\mathrm{P}_{2 \mathrm{~b}}$ & $200 \times 110 \times 240$ & 0.39 & 5.29 & 1086.01 & 1.25 \\
\hline
\end{tabular}

Table 6: results of all geometries studied

\begin{tabular}{ccccccccccccc}
\hline & \multicolumn{3}{c}{$\mathrm{U}_{\mathrm{g}}\left(\mathrm{W} \cdot \mathrm{m}^{-2} \cdot \mathrm{K}^{-1}\right)$} & \multicolumn{4}{c}{$\mathrm{q}_{\mathrm{HX}}(\mathrm{kW})$} & \multicolumn{5}{c}{$\mathrm{q}_{\mathrm{HX}} / \mathrm{m}\left(\mathrm{kW} \cdot \mathrm{kg}^{-1}\right)$} \\
$\mathrm{v}_{\text {air }}$ & 1 & 2 & 3 & 4 & 1 & 2 & 3 & 4 & 1 & 2 & 3 & 4 \\
\hline $\mathrm{M}_{\text {com }}$ & 22.7 & 24 & 25.57 & 27.57 & 2.64 & 4.45 & 5.58 & 6.46 & 2.16 & 3.64 & 4.5 & 5.29
\end{tabular}




\begin{tabular}{ccccccccccccc}
$\mathrm{M}_{\mathrm{cla}}$ & 17.74 & 24.34 & 25.02 & 26.16 & 1.92 & 3.08 & 3.58 & 3.96 & 1.05 & 1.68 & 1.96 & 2.16 \\
$\mathrm{P}_{1 \mathrm{a}}$ & 23.41 & 26.12 & 28.18 & 29.98 & 2.81 & 4.96 & 6.5 & 7.76 & 3.19 & 5.63 & 7.42 & 8.82 \\
$\mathrm{P}_{1 \mathrm{~b}}$ & 27.24 & 31.60 & 34.08 & 38.24 & 2.7 & 4.5 & 5.8 & 7.04 & 2.11 & 3.57 & 4.56 & 5.51 \\
$\mathrm{P}_{2 \mathrm{a}}$ & 31.3 & 34.04 & 36.57 & 38.95 & 2.87 & 5.33 & 7.66 & 9.28 & 4.22 & 7.83 & 11.3 & 13.6 \\
$\mathrm{P}_{2 \mathrm{~b}}$ & 45.07 & 45.54 & 46 & 46.25 & 2.75 & 4.75 & 6.27 & 7.34 & 2.18 & 3.75 & 4.95 & 5.8 \\
\hline
\end{tabular}

\subsection{Heat exchanged duty}

Figure 10a and table 6 show that despite the low thermal conductivity of polymer, $\left(\mathrm{k}_{\mathrm{al}}=237 \mathrm{k}_{\mathrm{polymer}}=17.2 ; 20\right.$ times lower than aluminum), all compact polymer HXs presented a heat exchange value much higher than metallic HXs: $\mathbf{P}_{\mathbf{1 b}}$ had the lower $\mathbf{q}_{\mathbf{H X}}$ between polymer geometries and it showed a $\mathbf{q}_{\mathbf{H X}} 78 \%$ more than $\mathbf{M}_{\mathrm{cla}}$ and $16 \%$ than $\mathbf{M}_{\text {com }}$. This large increase between polymer HXs and $\mathbf{M}_{\mathrm{cla}}$ was due to the enhancement of heat exchange area, it was 1.5 to 2.3 times greater than $\mathbf{M}_{\text {cla }}$ (table 5). Contrariwise, $\mathbf{M}_{\text {cla }}$ had a similar heat exchange area as polymer geometries configurations ' $\mathbf{a}$ ' and higher than configurations ' $\mathbf{b}$ '. In this case, the $16 \%$ increase noticed was linked to the reduction of the weak zone downstream of tubes: in this zone the heat flux was very low (figure 11). As well as the conducto-convective coupling, the low thermal conductivity of the material was compensated by enhancement of the convection heat coefficient of the air. In fact in forced convection, the heat flux depends on the geometric parameters according to the following equations (eq15-17):

By definition: $\mathbf{N u} \sim \mathbf{R e}^{\mathbf{n}}$ Avec $\mathrm{n}<1$

Re $\sim$ I With I: characteristic dimension

Moreover $\mathbf{h}=\frac{\mathrm{kNu}}{l}$

So: $\mathbf{h} \sim \frac{\mathbf{l}^{\mathrm{n}}}{\mathrm{l}} \sim \frac{\mathbf{1}}{\mathbf{1}^{1-\mathrm{n}}}$

Hence, the reduction of geometric parameters was expected to have a positive effect on ' $\mathbf{h}_{\text {air }}$ '. In addition, the absence of thermal resistance contact, estimated as $10 \%$ of global thermal resistance of HX [28] added a slightly advantage for the polymer HX.

It was observed that the configurations ' $\mathbf{b}$ ' for each geometry showed a global heat coefficient ' $\mathbf{U}_{\mathbf{g}}$ ' higher than configurations ' $\mathbf{a}$ ', it was $21.44 \%$ and $33.6 \%$ more (as average for all air inlet velocities). In fact, the increases in the fin thickness and fin pitch aroused two advantages: (i) the first one augmented the heat flux through the fins and the second one induced the development of horse-shoes vortices (figure 10) known to be in favor of the heat transfer (the development of these vortices is more important for larger Fp [29]). But the global heat transfer duty was lower than configurations a, because of a lower compactness for configurations b (table 4).

\subsection{Pressure Drop}

Pressure drop per length unit for all compact HX was higher than ' $\mathbf{M}_{\mathrm{cla}}$ ', this was due to the high compactness of these geometries, 2.5 till 3.8 time higher than $\mathrm{B}_{\text {ref2 }}$ (figure 9c, table 5). This problem could be limited by reducing the depth ' $\mathbf{L}_{\mathbf{y}}$ ' of the heat exchanger and the air inlet velocity ' $\mathbf{v}_{\mathbf{a}}$ '. In fact, heat exchanged duty and pressure drop augment simultaneously with air inlet velocity, knowing that the compact heat exchanger (' $\mathbf{M}_{\mathbf{c o m}}$ ' and all polymer HX) were able to provide the same heat performance for a smaller air inlet velocity. Hence, figure 9d shows that the compact HXs presented a heat performance ' $\mathbf{q}_{\mathbf{H x}}$ ' higher than ' $\mathbf{M}_{\mathrm{cla}}$ ' with a lower air inlet velocity and by the following lower pressure drop (figure 10c).

\subsection{Global performance}

An optimal geometry that had the best compromise between the highest heat exchange duties with the lowest ventilation power could be identified. While focalizing on the highest performance achieved with metallic HX ' $\mathbf{M}_{\text {com }}$ ' $\left(\mathrm{q}_{\mathrm{HX}}=6.46 \mathrm{~kW}, \mathrm{Pv}=40 \mathrm{~W}\right.$ ), it could be seen that for polymer $\mathrm{HX}$ a greater heat exchanged value was

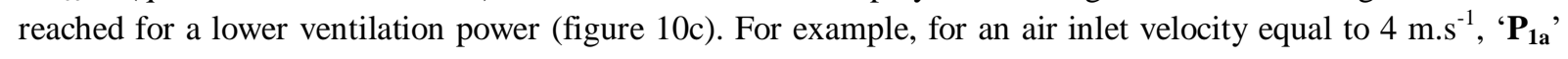
and ' $\mathbf{P}_{\mathbf{1 b}}$ ' showed a ' $\mathbf{q}_{\mathbf{H x}}$ ' $20 \%$ and $9 \%$ more than ' $\mathbf{M}_{\mathbf{c o m}}$ ' with a ventilation power $1.3 \%$ and $29 \%$ lower 
respectively. Concerning ' $\mathbf{P}_{2 \mathrm{a}}$ ' and ' $\mathbf{P}_{\mathbf{2 b}}$ ' they presented the best compromise between thermal performance and ventilation power.

The mass of the exchanger is also a very important parameter in certain applications such as automotive and aeronautics. Thus, these results came with a mass reduction of $40.8 \%$ comparing geometries ' $\mathbf{M}_{\text {com }}$ ' and $\mathbf{P}_{\mathbf{1 a}}$ and of $30.5 \%$ comparing $\mathbf{M}_{\text {cla }}$ and $\mathbf{P}_{\mathbf{1 b}}$ (table 4). For an air inlet velocity of $4 \mathrm{~m} . \mathrm{s}^{-1}, \mathbf{P}_{\mathbf{2}}$ and $\mathbf{P}_{\mathbf{2 b}}$ presented a thermal power by mass unit $\left(\mathrm{W} \cdot \mathrm{Kg}^{-1}\right) 257 \%$ and $109 \%$ greater than $\mathbf{M}_{\mathrm{com}}$ and 629 and $268 \%$ than $\mathbf{M}_{\mathrm{com}}$ (table 6).

a)

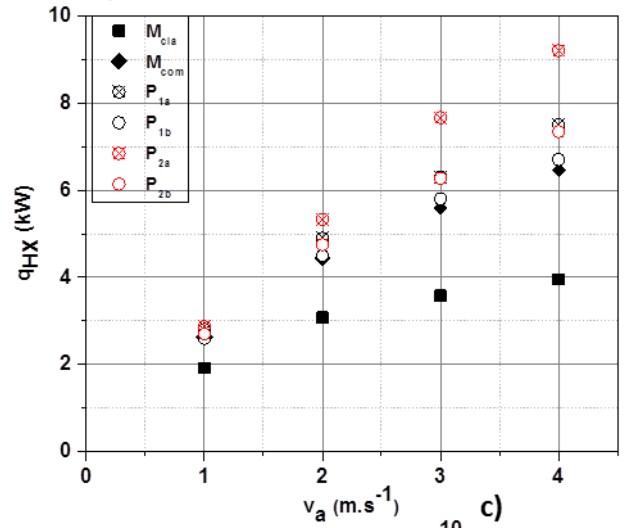

b)

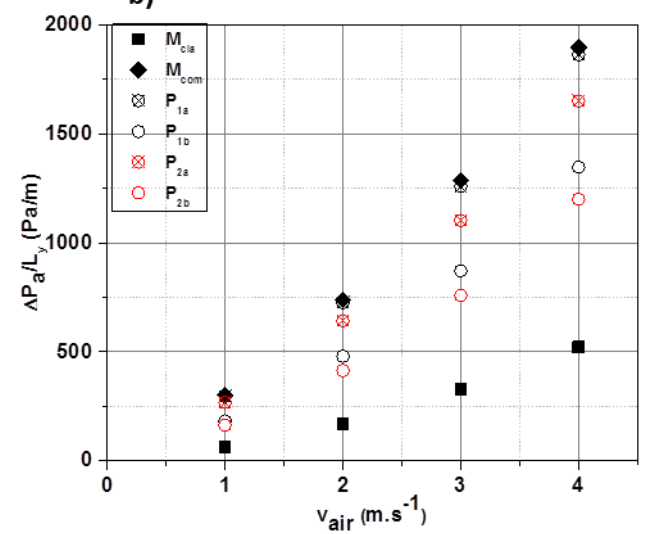

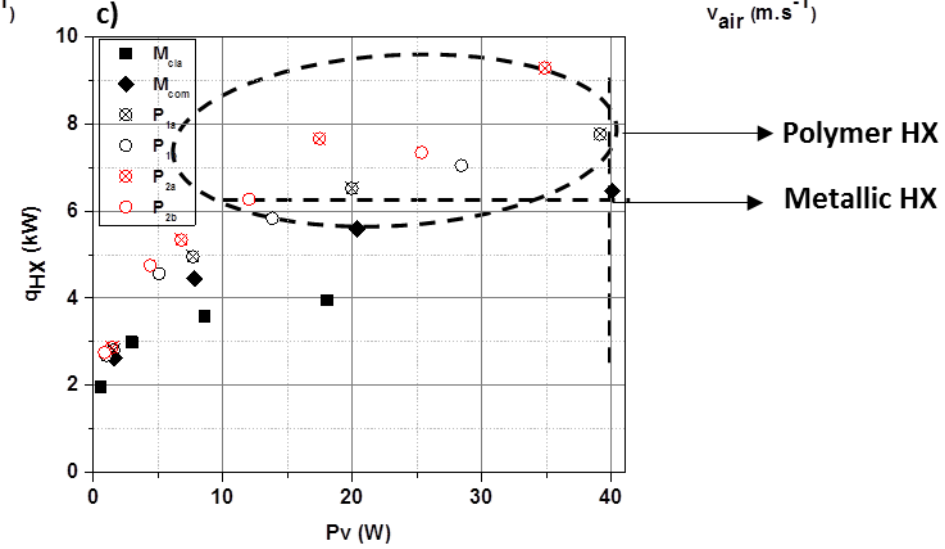

Figure 10: a) heat exchange duty function of air inlet velocity; b) pressure drop per length unit function of air inlet velocity; c) heat exchange duty function of ventilation power

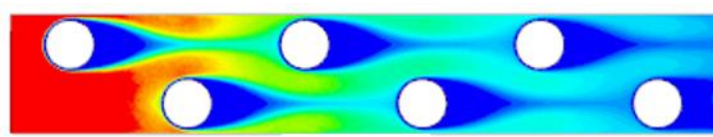

$\mathbf{M}_{\text {cla }}$

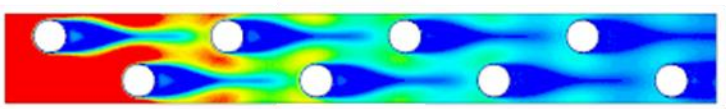

$\mathbf{P}_{1 \mathrm{a}}$

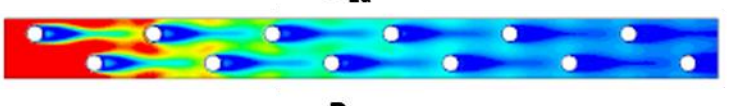

$\mathbf{P}_{2 \mathrm{a}}$

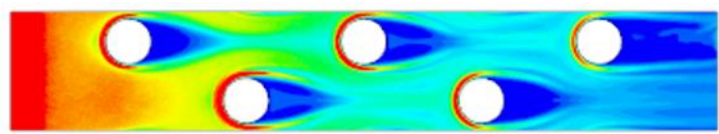

$\mathbf{M}_{\text {com }}$

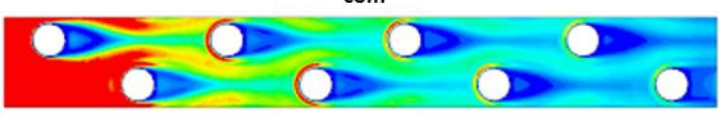

$\mathbf{P}_{1 \mathrm{~b}}$

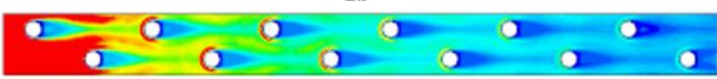

$\mathbf{P}_{2 \mathrm{~b}}$

40.000

50.000

Figure 11: heat flux coefficient of all geometries studied for air inlet velocity $2 \mathrm{~m} \cdot \mathrm{s}^{-1}$ 


\section{Conclusion}

The present study proved the advantages of the finned-tubes filled polymer HX, the low thermal conductivity of the materials did not present a handicap in this type of application, the results presented in this work showed that:

- The reduction of the geometrical parameters and the higher compactness of the HX could compensate the low thermal conductivity of the material. This could be seen as a passive method for enhancing heat transfer

- The compact polymer heat exchangers proved a gain in the thermal performance and a reduction in the pressure drops from the air side and in the mass of HX: configurations a with fin thickness $0.1 \mathrm{~mm}$ presented an interesting advantages regarding weight and thermal performance, and configurations $b$ with fin thickness $0.25 \mathrm{~mm}$ regarding ventilation power and thermal performance.

- The compact polymer HXs gave huge advantages comparing to a metal classic HXs: enhancement of 46.06 till $73.05 \%$ of heat exchange duty, reduction of $57.5 \%$ till $76.1 \%$ of ventilation power and decrease of 30.5 till $62.2 \%$ of weight.

- The comparison between compact metal HXs and polymers HXs, showed that the last had important advantages: $8.9 \%$ till $43.65 \%$ enhancement of heat exchange duty, reduction of $1.82 \%$ up to $36.7 \%$ in ventilation power and decrease of $40.8 \%$ and $45.6 \%$ of mass.

- This work could be a starting point for two axes of research: (i) use of various technic of thermal transfer enhancement in polymer finned-tube geometry as the modification of the tubes and fins shape to increase their thermal performance. (ii) Study the mechanical resistance of this type of HX, their ability to withstand operating conditions such as the pressure of fluid and vibrations in certain applications such as vehicles.

\section{Acknowledge}

The authors express their thanks to ADEME for the co-financing of this thesis subject with IMT Lille Douai, Institut Mines-Télécom.

\section{Reference}

[1] S. Shen, A. Henry, J. Tong, R. Zheng, and G. Chen, "Polyethylene nanofibres with very high thermal conductivities.," Nat. Nanotechnol., vol. 5, no. 4, pp. 251-5, 2010.

[2] J. Cevallos, A. Bar-Cohen, and D. C. Deisenroth, "Thermal performance of a polymer composite webbed-tube heat exchanger," Int. J. Heat Mass Transf., vol. 98, pp. 845-856, 2016.

[3] L. E. Mamunya YP, Davydenko VV, Pissis P, "Electrical and thermal conductivity of polymers filled with metal powders.," Eur Polym J, vol. 38, pp. 1887-97, 2002.

[4] X. Chen, Y. Su, D. Reay, and S. Riffat, "Recent research developments in polymer heat exchangers - A review," Renew. Sustain. Energy Rev., vol. 60, pp. 1367-1386, 2016.

[5] L. Zaheed and R. J. J. Jachuck, "Review of polymer compact heat exchangers, with special emphasis on a polymer film unit," Appl. Therm. Eng., vol. 24, no. 16, pp. 2323-2358, 2004.

[6] C. T'Joen, Y. Park, Q. Wang, A. Sommers, X. Han, and A. Jacobi, “A review on polymer heat exchangers for HVAC\&R applications," Int. J. Refrig., vol. 32, no. 5, pp. 763-779, 2009.

[7] J. Zhao, B. Li, X. Li, Y. Qin, C. Li, and S. Wang, "Numerical simulation of novel polypropylene hollow fiber heat exchanger and analysis of its characteristics," Appl. Therm. Eng., vol. 59, no. 1-2, pp. 134-141, 2013.

[8] X. Yan, B. Li, B. Liu, J. Zhao, Y. Wang, and H. Li, “Analysis of improved novel hollow fiber heat exchanger,” Appl. Therm. Eng., vol. 67, no. 1-2, pp. 114-121, 2014.

[9] Scheffler, T.B., and Leao, A.J., "Fabrication of Polymer Film Heat Transfer Elements for Energy Efficient Multi- Effect Distillation," Desalination, vol. 222, no. 1-3, p. 696-710, 2008.

[10] S. K. Zarkadas DM, "Polymeric hollow fiber heat exchangers: an alternative for lower temperature applications.," Ind EngChem Res, vol. 43, pp. 8093-106, 2004.

[11] K. Harris, C., Despa, M., and Kelly, "Design and Fabrication of a Cross FlowMicro Heat Exchanger," J. Microelectromechanical Syst., vol. 9, no. 4, p. pp.502-508, 2000.

[12] J. H. K. Haertel and G. F. Nellis, "A fully developed flow thermofluid model for topology optimization of 3D-printed air-cooled heat exchangers," Appl. Therm. Eng., vol. 119, pp. 10-24, 2017.

[13] L. Chen, Z. Li, and Z. Y. Guo, "Experimental investigation of plastic finned-tube heat exchangers, with emphasis on material thermal conductivity," Exp. Therm. Fluid Sci., vol. 33, no. 5, pp. 922-928, 2009.

[14] F.R. Menter, "Two-equation eddy-viscosity turbulence models for engineering applications," AIAA J., p. 1598e1605, 1994.

[15] B. B. K. Khallaki, S. Russeil, "Numerical study of the horseshoe vortex structure upstream a single plate-finned tube," Int. J. Heat Technol., pp. 31-36, 2005.

[16] U.O. Unal, M. Atlar, O. Goren, "Effect of turbulence modelling on the computation of the near-wake flow of a circular cylinder," Ocean Eng., pp. 387-399, 2010. 
[17] J. Voguelin, S. Tala, S. Russeil, D. Bougeard, and J. Harion, "Numerical analysis of the fin spacing effect on the horseshoe vortex system evolution in a heat exchanger," Int. J. Numer. Methods Heat Fluid Flow, vol. 23, no. 7, pp. 1136-1154, 2012.

[18] F. E. Division et al., "Procedure for Estimation and Reporting of Uncertainty Due to Discretization in CFD Applications," J. Fluids Eng., vol. 130, pp. 1-4, 2008.

[19] W. C.-C. Wang C.-C., Chi K.Y, "Heat transfer and friction characteristics of plain fin-and-tube heat exchangers, part II: Correlation," Int. J. Heat Mass Transf., vol. 43, no. 7, pp. 1136-1154, 2000.

[20] J.-Y. J. Jin-Sheng Leu, Ying-Hao Wu, "Heat transfer and fluid flow analysis in plate-fin and tube heat exchangers with a pair of block shape vortex generators," Int. J. Heat Mass Transf., vol. 47, pp. 4327-4338, 2004.

[21] C. Nyung, J. Jeong, and B. Youn, "Evaluation of thermal contact conductance using a new experimental-numerical method in fin-

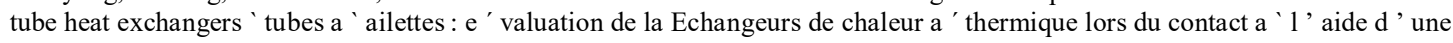
nouvelle conductivite ' tho," vol. 26, pp. 900-908, 2003.

[22] S. R. et B. B. D. BOUGEARD, S. DEVROE, "Comparaison de résultats expérimentaux et numériques concernant la prédiction des performances d'échangeurs multitubulaires à ailettes planes continues.," in Société Française de Thermique, SFT, 1996.

[23] J. Jeong, C. N. Kim, B. Youn, and Y. S. Kim, "A study on the correlation between the thermal contact conductance and effective factors in fin-tube heat exchangers with $9.52 \mathrm{~mm}$ tube," Int. J. Heat Fluid Flow, vol. 25, no. 6, pp. 1006-1014, 2004.

[24] B. L. Erek, A., Ozerdem, B., "Effect of geometrical parameters on heat transfer and pressure drop charactristics of plate fin and tube heat exchangers," Appl. Therm. Eng. Therm. Eng, vol. 25, pp. 2425-2431, 2005.

[25] K. P. Jabbour J, Bougeard D, Russeil S, Lacrampe M-F, "Performances d'un échangeur à tubes et ailettes en polymère : influence de la compacité et de la conductivité thermique," in 13ème Colloque Interuniversitaire Franco-Québécois Thermique des systèmes, Saint-Lô, France, 2017, p. ART-02-16.

[26] I. O. for Standardization, "Transient plane heat source (hot disc) method," 2008.

[27] B. Y. c Jin Jeong a, Chang Nyung Kim b, *, "A study on the thermal contact conductance in fin-tube heat exchangers with $7 \mathrm{~mm}$ tube," Int. J. Heat Mass Transf., vol. 49, pp. 1547-1555, 2006

[28] C. N. Kim, J. Jeong, and B. Youn, "Evaluation of thermal contact conductance using a new experimental-numerical method in fintube heat exchangers," Int. J. Refrig., vol. 26, no. 8, pp. 900-908, 2003.

[29] J. V. Simo Tala, S. Russeil, D. Bougeard, and J. L. Harion, "Investigation of the flow characteristics in a multirow finned-tube heat exchanger model by means of PIV measurements," Exp. Therm. Fluid Sci., vol. 50, pp. 45-53, 2013. 